\title{
Multifocal osteonecrosis related to steroid treatment in a patient with ulcerative colitis
}

\author{
P V Madsen, G Andersen
}

Abstract

A case of multifocal steroid related osteonecrosis in a patient with ulcerative colitis is presented. The pathogenesis, diagnosis, natural history, and treatment of the disease is discussed briefly with emphasis on the importance of early diagnosis - preferably by magnetic resonance imaging. Early diagnosis often depends on the gastroenterologist considering the possibility of oesteonecrosis.

(Gut 1994; 35: 132-134)

Aseptic (avascular) osteonecrosis is an adverse effect of systemic steroid treatment. ${ }^{1}$ Osteonecrosis has been recognised during or after steroid treatment in several conditions such as renal homotransplants, lupus erythematosus, asthma, etc whereas osteonecrosis is reported only rarely during treatment with systemic steroids in ulcerative colitis and Crohn's disease. ${ }^{23}$

We wish to draw attention to this rarely diagnosed but very serious complication to systemic steroid treatment of ulcerative colitis and the importance of magnetic resonance imaging for early recognition.

\section{Case report}

A 21 year old athletic man who was a painter and had a history of good health was admitted to hospital with suspected ulcerative colitis. The diagnosis of ulcerative pancolitis was confirmed endoscopically with biopsy. Treatment was started with systemic prednisolone $40 \mathrm{mg}$ twice daily and mesalazine $500 \mathrm{mg}$ thrice daily. The steroid dose was soon halved, but immediately had to be increased again.

The patient complained of spontaneous pain diffusely in the right knee two months after the first bowel symptoms, 28 days after the start of prednisolone treatment, and after a cumulative dose of $2 \cdot 3 \mathrm{~g}$. Clinical examination of the knee showed nothing abnormal. The pain subsided within few days after treatment with ibuprofen and ultrasound applied locally.

Prednisolone was stopped after seven months'

Departments of

Orthopedic Surgery and Diagnostic Radiology, Hjørring Sygehus, Hjørring, Denmark P V Madsen

G Andersen

Correspondence to: Dr P V Madsen,

Thoraxkirurgisk Afdeling,

Aalborg Sygehus Syd,

Hobrovej, DK 9000 Aalborg, Denmark.

Accepted for publication 12 May 1993 treatment and a cumulative dose of $8.6 \mathrm{~g}$, and the bowel disease stayed quiescent.

The patient complained of intermittent pain in both knees after heavy work at subsequent outpatient clinics. Twenty two months after the first signs of bowel symptoms, 20 months after the first complaint of knee pain, and 14 months after finishing steroid treatment both knees were clinically normal. Radiographs of the knees were erroneously interpreted as showing osteochondritis dissecans. He developed stress

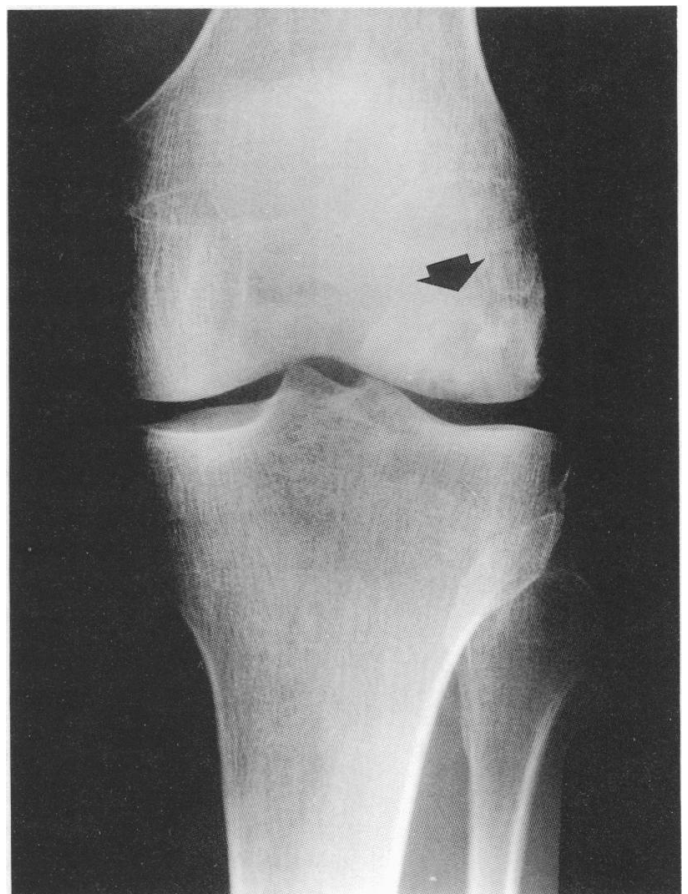

Figure 1: Radiograph of the left knee showing osteonecrotic lesion in the lateral condyle 29 months after starting treatment with systemic prednisolone.

induced swelling of both knees and the right elbow.

Osteonecrosis was mentioned for the first time when the patient was seen by an orthopaedic surgeon with new radiographs (see Figs 1 and 3) 30 months after the first bowel symptoms. After advanced osteonecrosis in both knees and the right elbow had been diagnosed by pain radiographs, it was confirmed by magnetic resonance imaging (see Figs 2 and 4). The patient was recommended to give up his present job and to seek an occuption that was less demanding on his legs and arms.

\section{Discussion}

Osteonecrosis is believed to be a result of ischaemia of the juxta-articular bone for either a short or long time. Sequestration of articular surfaces similar to oesteochondritis dissecans or collapse of subchondral bone with chondral injury occurs afterwards. The condition is found most commonly in the femoral head, but identical changes have been described in the proximal humerus, elbow, knee, and foot. ${ }^{1-5}$

No dose response relation exists between steroid treatment and the risk of oesteonecrosis. Seven days' treatment with a cumulative dose of dexamethasone equivalent to $0.75 \mathrm{~g}$ prednisolone has been followed by osteonecrosis with the 


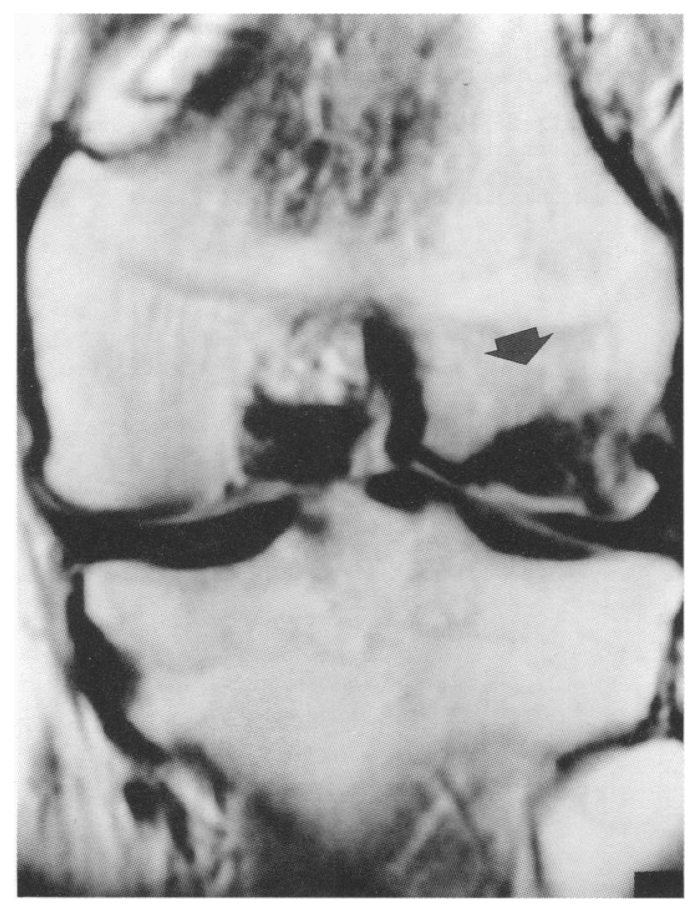

Figure 2: Magnetic resonance imaging of the left knee showing the same lesion as in Figure 1 one month later.

appearance of symptoms two years later, ${ }^{4}$ whereas most patients receiving steroids, do so for long periods and in higher doses without developing articular symptoms.

Osteonecrosis often begins insidiously and is difficult or impossible to diagnose with conventional radiography and computed tomography in the early stages. Scintigraphy may recognise oesteonecrosis somewhat earlier, but is rather uncertain because of poor anatomic resolution, false negative examinations with bilateral disease, and because the scintigraphic activity in the infarcted bone varies with the stage of the bone disease. Magnetic resonance imaging is a

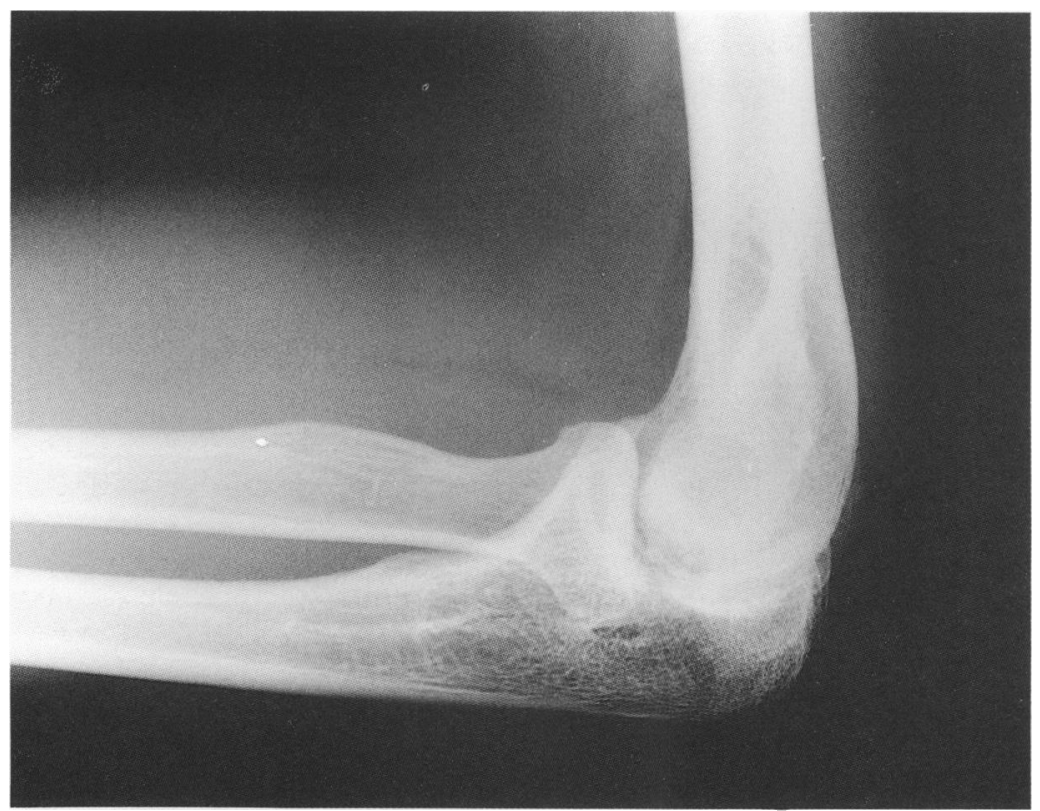

Figure 3: Radiograph of the right elbow showing nothing abnormal 29 months after starting treatment with systemic prednisolone.

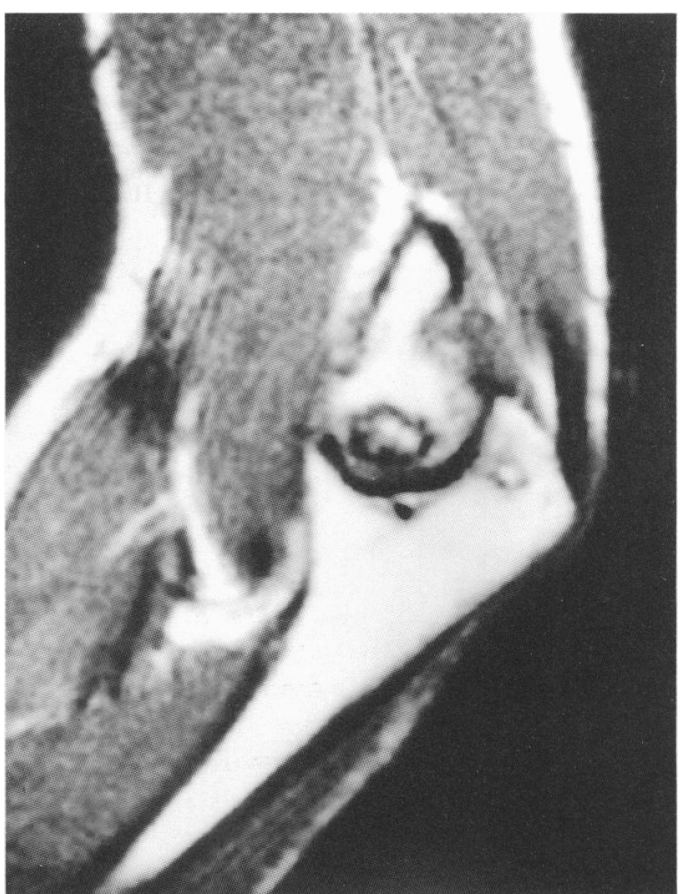

Figure 4: Magnetic resonance imaging one month after the radiograph in Figure 3 showing osteonecrotic lesions subchondrally in trochlea and olecranon of the right elbow.

non-invasive method, which shows very early osteonecrotic changes and which is in good agreement with pathoanatomical findings. ${ }^{5-9}$

The clinical course of osteonecrosis is unpredictable in the individual case but it often disables the patient and results in need for alloplastic joint operations. If osteonecrosis is diagnosed early enough, collapse of the subchondral bone and progression of the disease may be averted in some patients by decreasing the stresses across the affected joint and by training mobility. Although there is little evidence that any treatment changes the natural course of osteonecrosis, early diagnosis is important to be able to recommend the patient possible new job training, etc. Surgically different approaches (for example, curettage, core decompression, and bone transplant) have been tried with somewhat contradictory results. Osteotomies have been used too, but the ultimate treatment is often an alloplastic joint operation..$^{1-3}$

In conclusion osteonecrosis is rarely seen, but often becomes debilitating, and is difficult to diagnose with most imaging techniques. We propose that inflammatory bowel disease patients who are or have been treated with systemic steroids and have articular complaints are investigated for osteonecrosis preferably by magnetic resonance scanning.

1 Cruess RL. Steroid-induced osteonecrosis: a review. Can f Surg 1981; 24: 567-71

2 Vakil N, Sparberg M. Steroid-related osteonecrosis in inflammatory bowel disease. Gastroenterology 1989; 96: 62-7.

3 Sasaki T, Yagi T, Monji JI, Yasuda K, Masuda T. Steroidinduced osteonecrosis of the femoral condyle - a clinical study of eighteen knees in ten patients. $\mathscr{J} \mathcal{J}$ pn Orthop Assoc 1986; 60: of eighte.

4 Anderton JM, Helm R. Multiple joint osteonecrosis following short-term steroid therapy. F Bone foint Surg [Am] 1982; 64:

5 Gillespy T, Genant HK, Helms CA. Magnetic resonance imaging of oesteonecrosis. Radiol Clin North Am 1986; 24: 193-208. 
6 Bassett LW, Gold RH, Reicher M, Bennett LR, Tooke SM. Magnetic resonance imaging in the early diagnosis of ischemic necrosis of the femoral head. Clin Orthop 1987; 214:

237-48.

7 Mitchell MD, Kundel HL, Steinberg ME, Kressel HY, Alavi A, Axel L. Avascular necrosis of the hip: comparison of MR, CT, and scintigraphy. AfR 1986; 147: 67-71.

8 Robinson HJ, Hartleben PD, Lund G, Schreiman J. Evaluation of magnetic resonance imaging in the diagnosis of osteonecrosis of the femoral head. F Bone Foint Surg [Am] 1989; 71: $650-63$.

9 Seiler JG, Christie MJ, Homra L. Correlation of the findings of magnetic resonance imaging with those of bone biopsy
in patients who have stage-I or II ischemic necrosis of the femoral head. I Bone foint Surg [Am] 1989; 71: the fe. 